\title{
PURIFICATION AND PARTIAL AMINO ACID SEQUENCE OF THE GLUTAMATE 1-SEMIALDEHYDE AMINOTRANSFERASE OF BARLEY AND SYNECHOCOCCUS
}

by

\author{
BERNHARD GRIMM, ALAN BULL"), KAREN G. WELINDER ${ }^{2)}$, SIMON P. GOUGH \\ and C. GAMINI KANNANGARA
}

\author{
Department of Physiology, Carlsberg Laboratory, \\ Gamle Carlsberg Vej 10, 2500 Copenhagen Valby \\ 1Department of Biochemistry, The University College of Wales, \\ Penglais, Aberystwyth, UK \\ ${ }^{2}$ Department of Biochemical Genetics, University of Copenhagen, \\ $\varnothing$. Farimagsgade 2A, 1353 Copenhagen $\mathrm{K}$.
}

Keywords: Aminolevulinate synthesis, chlorophyll

\begin{abstract}
Glutamate-1-semialdehyde aminotransferase (E.C. 5.4.3.8) was purified from barley and the cyanobacteria Synechococcus PCC 6301. The purification procedure involved serial affinity chromatography and preparative polyacrylamide gel electrophoresis under non-denaturing conditions. The aminotransferase of these two organisms showed different mobilities in non-denaturing gels. In SDS-PAGE the enzyme from both organisms migrated as a single protein with an apparent molecular weight of $46.000 \mathrm{Da}$. An antibody against the barley enzyme cross-reacted with the cyanobacterial aminotransferase. This antibody also recognized a $17 \mathrm{kDa}$ peptide cleaved from the barley protein with cyanogen bromide. Amino acid sequences of the $\mathrm{NH}_{2}$-termini revealed significant homology between the eucaryotic and cyanobacterial enzyme.
\end{abstract}

\section{INTRODUCTION}

Chlorophyll synthesis is regulated at the steps forming $\delta$-aminolevulinate from glutamate. Glutamate 1-semialdehyde aminotransferase (E.C. 5.4.3.8) catalyses the last step in the tRNA ${ }^{\text {Glu }}$ mediated pathway for aminolevulinate synthesis. It is a soluble protein present in higher plants and in many bacteria (4). In plants it is located in the stroma of greening plastids and is encoded in the nuclear genome.

The conversion of glutamate 1-semialdehyde to $\delta$-aminolevulinate requires the donation of an amino group to glutamate 1 -semialdehyde most likely by the formation of the intermediate 4,5-diaminovalerate (2). Subsequent transfer of the 4-amino group to the enzyme then liberates

Abbreviations: $\mathrm{ALA}=\delta$-aminolevulinate; $\mathrm{CNBr}=$ cyanogen bromide; $\mathrm{DTT}=$ dithriotreitol; GSA = glutamate 1-semialdehyde; PAGE = polyacrylamide gel electrophoresis; PBG = porphobilinogen; PVDF = polyvinylidene diflouride; SDS = sodium-dodecylsulphate; Tricine = N-[Tris(hydroxymethyl)-methyl]-glycin. 

aminotransferase

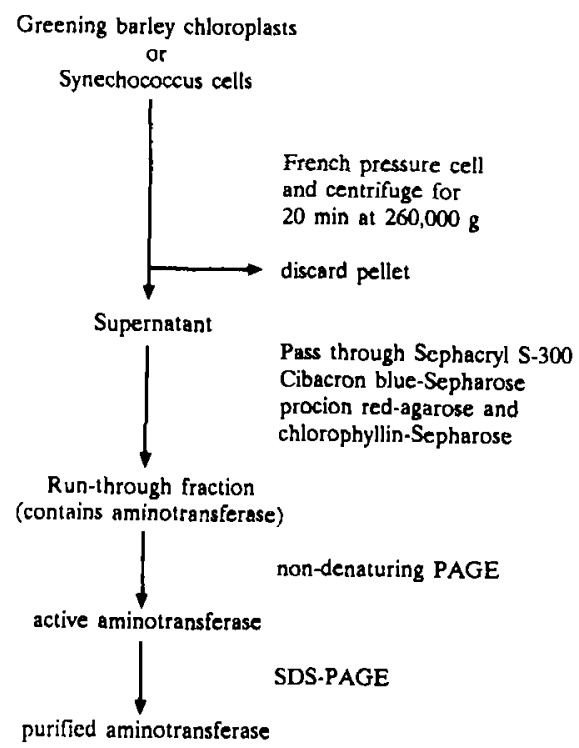

Figure 1. Flow diagram illustrating the procedure to purify glutamate 1-semialdehyde aminotransferase.

aminolevulinate and regenerates the amino form of the enzyme. As several other aminotransferases which require pyridoxamine phosphate as the amino donor the glutamate 1-semialdehyde aminotransferase is inhibited by gabaculine. Sensitivity to the inhibitor is restricted to the pyridoxal phosphate form of the enzyme (2).

However, positive identification of pyridoxamine phosphate as the cofactor for the aminotransferase has not been possible for the barley enzyme. Recently, we were able to show that pyridoxamine acts as an amino donor for the purified glutamate 1 -semialdehyde aminotransferase from the cyanobacterium Synechococcus (Bull et al., in preparation). It is therefore of interest to compare the primary structure of the enzymes and determine why added pyridoxamine phosphate cannot function with the partially purified barley enzyme (2). Towards this end, we present a purification procedure for the glutamate 1-semialdehyde aminotransferase from barley and Synechococcus which permitted us to obtain the sequence of 16 and $19 \mathrm{NH}_{2}$-terminal amino acid residues of the two enzymes.

\section{MATERIALS AND METHODS}

\subsection{Chemicals}

Methanol was obtained from Rathburn, Walkerburn, UK. Polyvinylidene diflouride microporous (PVDF) membranes (Immobilon) were purchased from Millipore, Bedford, MA, USA, nitrocellulose filters from Schleicher \& Schüll, Dassel, FRG, acrylamide from Bio-Rad Laboratories, Richmond, CA, USA.

\subsection{Starting material for the purification of the glutamate 1-semialdehyde aminotransferase of barley and Synechococcus}

Chloroplast stromal proteins were obtained from greening barley seedlings and soluble protein extracts were prepared from Synechococcus strain PCC 6301 grown photoautotrophically as described (13). Plastids were isolated from 6 day dark-grown barley seedlings (cv. Svalöf's Bonus), which were illuminated for $12 \mathrm{~h}$. Stroma proteins were prepared and subjected to serial affinity chromatography (Fig. 1) as described in $(6,15)$. Fifteen $g$ wet weight synechococcal cells were suspended in $50 \mathrm{ml}$ $0.7 \mathrm{M}$ sodium phosphate buffer, $\mathrm{pH} 7.5$ and disrupted by passing them twice through a French pressure cell. The suspension was centrifuged for $30 \mathrm{~min}$ at $260,000 \mathrm{~g}$ at $4{ }^{\circ} \mathrm{C}$. The supernatant referred to as the soluble protein extract was subjected to the affinity column system mentioned above (Fig. 1).

\subsection{Polyacrylamide gel electrophoresis for purification of active enzyme}

Electrophoresis in non-denaturing polyacrylamide slab gels $(30 \times 20 \mathrm{~cm} \times 0.7 \mathrm{~mm})$ was performed in a cold room to retain the activity of glutamate 1-semialdehyde aminotransferase. The separation gel contained $10 \%$ polyacrylamide, $0.38 \mathrm{M}$ Tris/HCl, pH 8.0, $10 \%$ glycerol and $4 \mathrm{mM}$ DTT and the stacking gel $4 \%$ polyacrylamide, $1 \mathrm{~mm}$ DTT, $56 \mathrm{~mm}$ Tris/HCl, $\mathrm{pH}$ 6.7 and $10 \%$ glycerol. The electrophoresis buffer consisted of $5 \mathrm{mM}$ Tris and $39 \mathrm{~mm}$ glycine, $\mathrm{pH}$ $8.3,4 \mathrm{~mm}$ thioglycolate and $1 \mathrm{~mm}$ DTT. Electrophoresis was carried out overnight $(18 \mathrm{~h})$ with a constant current of $28 \mathrm{~mA}$. 


\subsection{SDS-polyacrylamide gel electrophoresis}

Mainly two different SDS-gel systems were employed. Routinely the system described in (11) was used which contained $10 \%$ or $12.5 \%$ polyacrylamide. For the purpose of amino acid sequence determination proteins were separated in a Tricine-SDS-gel system $(12,14)$. These gels were prepared with different polyacrylamide concentrations depending on the size of the peptides in the samples. Cyanogen bromide generated peptides were separated in a 3 step gradient gel consisting of a $4 \%$ polyacrylamide stacking gel, a $10 \%$ spacer gel and a $16.5 \%$ separation gel. To facilitate electro-transfer for uncleaved proteins electrophoresis was carried out in a separation gel containing 7\% polyacrylamide overlaid by a $4 \%$ stacking gel.

Gels were subjected to a pre-electrophoresis for $5 \mathrm{~h}$ at $30 \mathrm{~mA}$ with $20 \mathrm{~mm}$ thioglycolate in the upper reservoir buffer (12). Samples dissolved in $4 \%$ SDS, $12 \%$ glycerol, $50 \mathrm{~mm}$ Tris and $2 \%$ mercaptoethanol were heated for $30 \mathrm{~min}$ at $40{ }^{\circ} \mathrm{C}$ and loaded on the gel. Electrophoresis was started with a constant voltage of $30 \mathrm{~V}$ until the samples migrated into the stacking gel and thereafter the current was set to $30 \mathrm{~mA}$ for the remaining run.

\subsection{Electro-blotting onto PVDF-membranes}

The proteins were transferred from gels to PVDF-membranes using a semidry blotting manifold (7). The gels were soaked in transfer buffer ( $5 \%$ methanol, $50 \mathrm{~mm}$ borate- $\mathrm{NaOH}, \mathrm{pH}$ $8.0)$ for $10 \mathrm{~min}$. The PVDF-membranes were immersed in $100 \%$ methanol and then equilibrated in transfer buffer. After soaking the gel was placed onto the PVDF-membrane and gel and membrane were sandwiched between $2 \times 2$ layers of Whatman $3 \mathrm{MM}$ paper. The current was set for $2 \mathrm{~h}$ at $0.4 \mathrm{~mA} / \mathrm{cm}^{2}$. After blotting the PVDF-membrane was stained in $0.1 \%$ Coomassie Blue R 250 (Serva) in 50\% methanol for one minute and destained in $40 \%$ methanol, $10 \%$ acetic acid for $10 \mathrm{~min}$. The filter was rinsed with double distilled $\mathrm{H}_{2} \mathrm{O}$. Protein bands were cut out, dried under nitrogen and stored at $-20^{\circ} \mathrm{C}$.

\subsection{Western blot analysis}

Anti-barley aminotransferase antibodies had been raised in rabbits. They cross-react with the Synechococcal enzyme. For immune assay proteins were separated in SDS-polyacrylamide gels and blotted onto nitrocellulose filters with the same semidry blot manifold mentioned under 2.5. The immune blotting assay of the immobilized proteins using peroxidase linked secondary antibodies raised against rabbit IgG as described in (1). Alternatively, secondary antibodies conjugated with alkaline phosphatase were used for the immune assays of the Synechococcal aminotransferase. In this case a TBST-buffer containing $10 \mathrm{~mm}$ Tris/ $\mathrm{HCl}, \mathrm{pH} 8$, $150 \mathrm{~mm} \mathrm{NaCl}, 0.05 \%$ Tween 20 was made up as incubation medium.

\subsection{Determination of the $\mathbf{N H}_{2}$-terminal amino acid sequence and the amino acid composition}

Microsequencing and amino acid analysis on PVDF-membrane blotted protein were performed as reported in (12).

\subsection{Enzyme assays}

\subsubsection{Glutamate 1-semialdehyde amino- transferase assays}

This enzyme was assayed in three different ways.

1. Direct assay using non-radioactive glutamate 1-semialdehyde:

Assay mixtures contained in $1 \mathrm{ml} 0.1 \mathrm{M}$ Tricine/ $\mathrm{NaOH}, \mathrm{pH} 7.9,0.3 \mathrm{~m}$ glycerol, $1 \mathrm{~mm}$ DTT, $25 \mathrm{mM} \mathrm{MgCl}_{2}$, ca. $25 \mu \mathrm{M}$ glutamate 1 -semialdehyde and ca. $100 \mu \mathrm{g}$ protein. Levulinate $(5 \mathrm{mM})$ was included in the assay mixture when the enzyme preparation contained $\delta$ aminolevulinate dehydratase. The assay mixtures were incubated for $20 \mathrm{~min}$ at $28^{\circ} \mathrm{C}$ and the reactions stopped by addition of $25 \mu \mathrm{l}$ of $70 \%$ perchloric acid. The precipitated protein was removed by centrifugation and the supernatant analysed for $\delta$-aminolevulinate after condensing it with ethylacetoacetate as previously described (2).

2. Direct assay using ${ }^{14} \mathrm{C}$-labelled glutamate 1-semialdehyde: 
The assay mixture contained in $100 \mu 10.1 \mathrm{M}$ Tricine/ $\mathrm{NaOH}, \mathrm{pH} 7.9,0.3 \mathrm{~m}$ glycerol, $1 \mathrm{~mm}$ DTT, $25 \mathrm{mM} \mathrm{MgCl}_{2},{ }^{14} \mathrm{C}$-glutamate 1-semialdehyde $(200,000 \mathrm{cpm})$ and ca. $25 \mu \mathrm{g}$ protein. Levulinate $(5 \mathrm{~mm})$ was included in the assay mixtures when the enzyme preparation contained $\delta$-aminolevulinate dehydratase. The assay mixtures were incubated for $20 \mathrm{~min}$ at $28^{\circ} \mathrm{C}$ and the reactions stopped by addition of $7 \mu$ l of $7 \%$ perchloric acid. The precipitated proteins were removed by centrifugation and the supernatants analysed for synthesis of $\delta$-aminolevulinate as previously described (15)

3. Coupled enzyme assay converting glutamate 1-semialdehyde to uroporphyrin:

The incubation mixture contained in $100 \mu \mathrm{l}$ $0.1 \mathrm{~m}$ Tricine/ $\mathrm{NaOH}, \mathrm{pH} 7.9,0.3 \mathrm{M}$ glycerol, 1 mM DTT, $25 \mathrm{~mm} \mathrm{MgCl}_{2}$, ca. $25 \mu \mathrm{M}$ glutamate 1-semialdehyde, aliquots of aminolevulinate dehydratase and porphobilinogen deaminase purified by chromatography with Sephacryl S200 (2) and glutamate 1-semialdehyde aminotransferase. The total amount of protein was 25 $\mu \mathrm{g}$ in the assay. The mixture was incubated for $20 \mathrm{~min}$ at $28^{\circ} \mathrm{C}$ and $5 \mu \mathrm{l}$ of $70 \%$ perchloric acid was added. The tubes were then placed under long wave ultra-violet light to complete the oxidation of uroporphyrinogen to uroporphyrin. One $\mathrm{ml}$ of $1 \mathrm{M} \mathrm{HCl}$ was added to the mixture and the precipitated proteins were removed by centrifugation. Uroporphyrin was quantitated by measuring the optical density of the supernatant at $406 \mathrm{~nm}$.

\subsubsection{Detection of $\delta$-aminolevulinate dehydratase and porphobilinogen deaminase in non-denaturing polyacrylamide gels}

The gels were incubated in a buffer containing 0.1 M Tricine/ $\mathrm{NaOH}, \mathrm{pH} 7.9,0.3 \mathrm{~m}$ glycerol, $1 \mathrm{mM}$ DTT, $25 \mathrm{~mm} \mathrm{MgCl}$ and either $10 \mathrm{~mm}$ $\delta$-aminolevulinate or $50 \mu \mathrm{M}$ porphobilinogen for $60 \mathrm{~min}$ at $30^{\circ} \mathrm{C}$. After incubation the gels were soaked either in Ehrlich's reagent for detection of the aminolevulinate dehydratase or in $70 \%$ perchloric acid for analysis of porphobilinogen deaminase. Deaminase activity was detected by fluorescence of urophorphyrin under ultra-violet light.

\subsection{Preparation of glutamate 1-semialdehyde aminotransferase by preparative isoelectric focussing}

The starting material for this enzyme preparation was a supernatant obtained after centrifugation of homogenized barley leaves at $4100 \mathrm{~g}$, which is usually discarded (see 2.2). Water insoluble polyvinylpyrrolidone (Polyclar AT) was added to this solution to a final concentration of $1 \%$. The mixture was adjusted to $\mathrm{pH} 7.9$ with solid Tricine and with ammonium sulphate to $30 \%$ saturation. After centrifugation at $7,500 \mathrm{~g}$ for $20 \mathrm{~min}$ the precipitate was discarded. The supernatant was saturated with ammonium sulphate up to $70 \%$ and centrifuged again. The supernatant was then discarded and the precipitate resuspended in $0.6 \mathrm{M}$ glycerol, $0.1 \mathrm{M}$ Tricine, pH 9.0 and $1 \mathrm{mM}$ DTT and subsequently desalted on a large Sephadex G-50 column into the same medium. Aliquots of the preparation were frozen at $-20{ }^{\circ} \mathrm{C}$.

A sample with $65 \mathrm{mg}$ of protein was centrifuged to remove a green precipitate and dialysed overnight against a large volume of $20 \%$ glycerol, $10 \mathrm{~mm}$ Tricine, pH 7.9, $1 \mathrm{~mm}$ DTT. Then it was applied to the preparative isoelectric focussing apparatus (Rotophor, Bio-Rad). Isoelectric focussing was performed for $2.5 \mathrm{~h}$ at $4^{\circ} \mathrm{C}$ using $2 \%$ ampholytes in the range of $\mathrm{pH} 3$ to 10 (Biolytes $3 / 10$, Bio-Rad) and $0.1 \%$ n-octyl$\beta$-D-glucoside. The voltage changed from 350 to $1000 \mathrm{~V}$ at constant power of 12 watts during the run. Fractions with aminotransferase activity were subjected again to isoelectric focussing without the addition of more ampholytes. Separation of the proteins was again performed at constant power of 12 watts.

\subsection{Protein cleavage with cyanogen bromide}

A purified glutamate 1-semialdehyde aminotransferase fraction of barley was desalted on a Sephadex G-50 column. About $1 \mathrm{mg}$ of protein was freeze-dried and dissolved in $500 \mu \mathrm{l} 70 \%$ formic acid. This solution was incubated with 10 mg cyanogen bromide overnight at room temperature. The mixture was dried under nitrogen and at the same time cyanogen bromide was removed. Finally, the precipitated peptides were dissolved in sample buffer for electrophoresis. 


\section{Coupled assay :}

\section{Glutamate 1-semialdehyde}
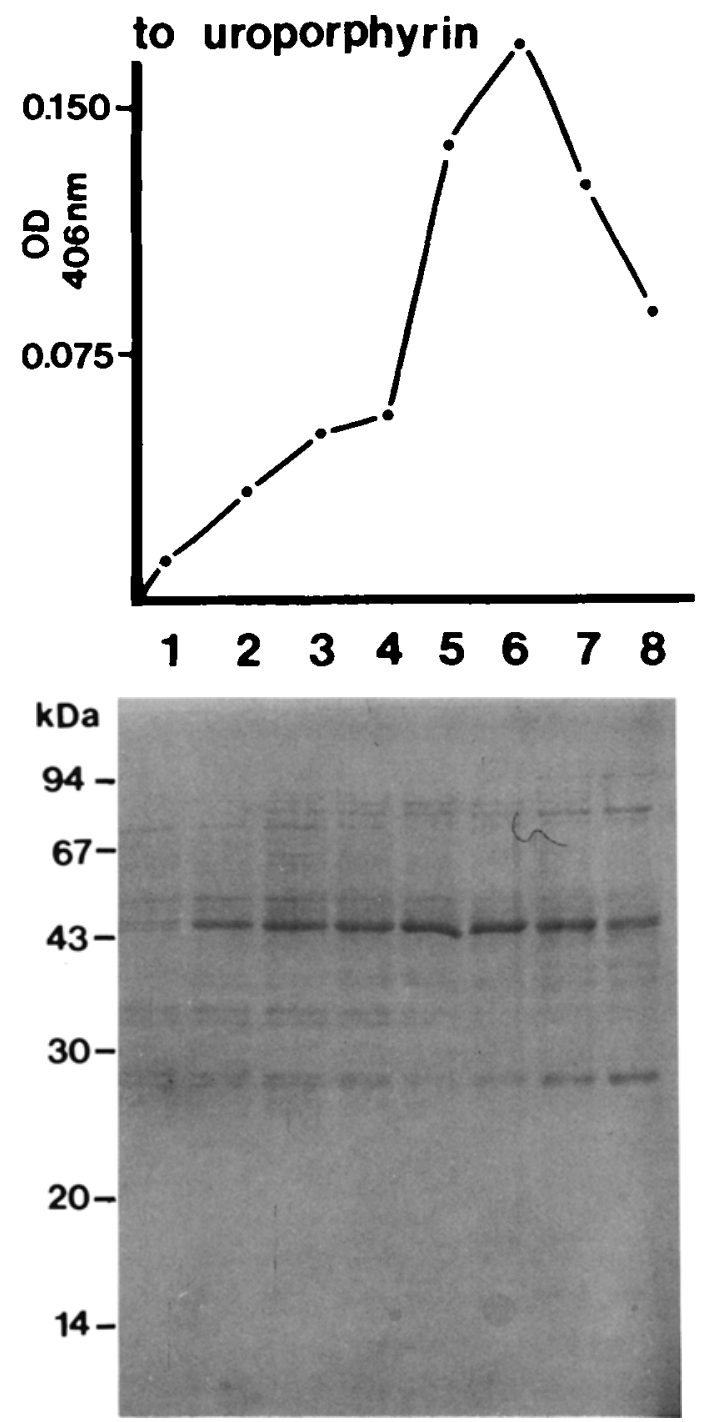

\subsection{Other methods}

For the antibody preparation aminotransferase was purified as previously described $(6$, 15). An active protein from a non-denaturing gel was injected into rabbits.

Absorption spectra were recorded on an Aminco DW 2 spectrophotometer.
Figure 2. Purification of glutamate 1-semialdehyde aminotransferase from barley. Stromal proteins were subjected to serial affinity chromatography. The runthrough fraction was separated in a non-denaturing gel. Protein eluted from $1 \mathrm{~mm}$ gel strips ( 1 to 8 ) was tested for GSA-aminotransferase activity in a coupled assay containing ALA-dehydratase and PBG-deaminase. Activity was determined by measuring the absorption of formed urophorphyrin at $406 \mathrm{~nm}$. In the lower panel of the figure an aliquot of the most active fraction and neighbouring fractions were denatured and separated in a $10 \%$ SDS-PAGE according to (11). Proteins were stained with Coomassie Blue. Bars on the left side indicate the molecular weight of marker proteins.

\section{RESULTS}

\subsection{Purification of the glutamate 1-semialdehyde aminotransferase of barley and Synechococcus}

Figure 1 presents a flow diagram of the purification procedure used for barley and Synechococcus glutamate 1 -semialdehyde aminotransferase. The separation of the glutamate 1-semialdehyde aminotransferase from the other enzymes and the tRNA ${ }^{\mathrm{Glu}}$ of the pathway was performed by passing the proteins obtained by solubilization with the French pressure cell through the Sephacryl S-300 column and the different affinity columns as described previously $(6,15)$.

The aminotransferase retained enzymatic activity up to the stage of polyacrylamide gel electrophoresis. It was previously reported that enzyme diminished its activity during electrophoresis under non-denaturing conditions (5). In order to avoid this loss the present separations were carried out in gels containing $1 \mathrm{~mm}$ DTT. However, after SDS-PAGE the enzyme lost all its activity and could be detected only by using the antiserum raised against electrophoretically purified aminotransferase.

Aliquots of the concentrated run-through fractions were applied to preparative non-denaturing gels. To avoid $\mathbf{N H}_{2}$-terminal blockage to amino acid sequencing a pre-electrophoresis run for at least $2 \mathrm{~h}$ was carried out with $20 \mathrm{~mm}$ thioglycolate in the upper electrophoresis buffer. Further precausions included charcoal treatment of the polyacrylamide and the use of twice 


\section{Glutamate-1-semialdehyde aminotransferase}

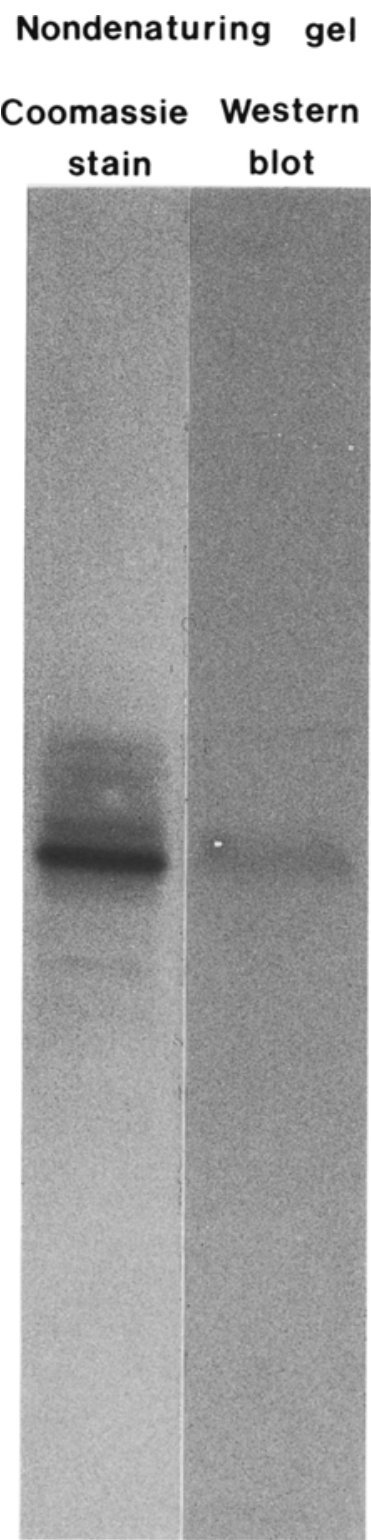

A

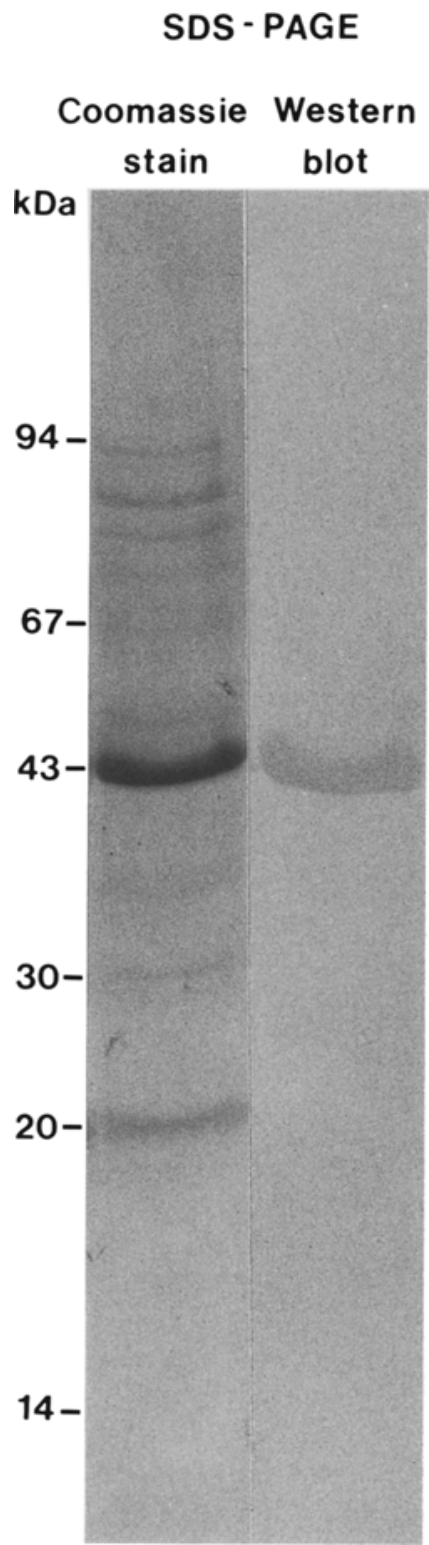

B

Figure 3. Identification of glutamate 1-semialdehyde aminotransferase from barley. A) The protein fraction with the highest aminotransferase activity obtained from a preparative gel separation of the run-through fraction (cf. Fig. 2) was re-run in a $10 \%$ non-denaturing gel. A prominent band could be stained with Coomassie Blue and reacted in a Western blot with an antibody against the barley aminotransferase. B) The protein fraction with the highest aminotransferase activity was separated in a 10\% SDS denaturing gel and probed in a Western blot with the antibody. A single band corresponding to a molecular mass of $46 \mathrm{kDa}$ is identified by the antibody. 
crystallized SDS for the SDS-gels.

After an overnight run with $28 \mathrm{~mA}$ the gels were horizontally cut into $1 \mathrm{~mm}$ strips and the eluted proteins were routinely assayed for aminotransferase in a coupled assay with aminotransferase free $\delta$-aminolevulinate dehydratase and porphobilinogen deaminase. These two enzymes are also present in the run-through protein fraction but it was established with appropriate enzyme assays, directly on the nondenaturing gel, that the dehydratase migrated slower than the aminotransferase. All four bands of the PBG-deaminase representing the four forms of the enzyme with different transition state substrates migrated faster than the aminotransferase. Therefore, these two enzymes were absent in the gel strips containing the aminotransferase and thus permitting the use of the coupled assay.

In non-denaturing gels one peak of activity was detected for the barley glutamate 1-semialdehyde aminotransferase (Fig. 2). An aliquot of each of the eluted $1 \mathrm{~mm}$ strips with activity was re-run on an SDS-polyacrylamide gel. These fractions contained a major Coomassie Blue stained band of $46 \mathrm{kDa}$ and several other proteins. The intensity of the major Cooomassie Blue stained band corresponded to the distribution of the activity of the glutamate 1-semialdehyde aminotransferase in the fractions. Accompanying protein bands do not correlate in intensity with the distribution of enzyme activity.

Western blots were made with the aminotransferase enriched fraction separated either in non-denaturing gels or in SDS-gels and probed with an antibody against glutamate 1 -semialdehyde aminotransferase (Fig. 3A + B). The fraction contained an abundant protein that is recognized by the antibody. In non-denaturing gels this protein migrates with an $\mathbf{R f}$-value of 0.44 , which is identical to the $\mathrm{Rf}$-value determined for the most active fraction in the preparative non-denaturing gel. In SDS-gels the antibody exclusively reacts with the $46 \mathrm{kDa}$ protein identified as aminotransferase in Figure 2.

Glutamate 1-semialdehyde aminotransferase of Synechococcus could be purified after electrophoresis of the run-through fraction. The protein which correlated with the activity peak of the aminotransferase had a higher mobility in the non-denaturing gel than that of barley. The $R f$ value of 0.63 indicates that the Synechococcal protein has a charge/size ratio different from the barley protein (Fig. 4).

The fraction with the highest aminotransferase activity was blotted onto nitrocellulose filter and this was probed with antiserum raised against the barley enzyme. For comparison a barley protein fraction with the maximal activity of aminotransferase was analysed on the same filter in the immune blot assay (Fig. 4). The antibody reacted in both species with one major protein band. That of Synechococcus had a higher mobility with an $\mathbf{R f}=0.63$ and that of barley the expected value of $\mathrm{Rf}=0.44$. An additional faster moving peptide was recognized by the antibody in both lanes of Figure 4A. It has the same mobility in both species and is perhaps a degradation product of the glutamate 1-semialdehyde aminotransferase.

The active fractions of Synechococcus were also separated in an SDS-gel and assayed with the antibody (Fig. 4B). The immune blot resulted in a cross-reacting $46 \mathrm{kDa}$ band which is identical in molecular mass with the barley protein. Its abundancy (Fig. 4B) in the fractions corresponds to the measured activity of the aminotransferase with a peak in lane 4 . The amount of enzymatic activities expressed as nmoles of $\delta$-aminolevulinate formed per assay were as follows: lane 2, 6.0; lane 3, 8.6; lane 4, 11.0; lane 5, 9.6; and lane 6, 5.9.

In lane 1 of Figure 4B the Western blot of the electrophoretically purified barley protein after separation in an SDS-containing gel is depicted. In this case the minor contaminating proteins gave cross-reactions with the antiserum. It cannot be decided, whether this is due to unspecific binding or the presence of antibodies against the accompanying proteins in the fraction. In conclusion, the antiserum recognizes a single 46 $\mathrm{kDa}$ protein in the aminotransferase preparation of Synechococcus, which has the same apparent molecular mass as the major antigenic protein of the barley preparation.

\subsection{Electro-transfer of proteins from} polyacrylamide gels to PVDF-membranes

In some cases the aminotransferase eluted from horizontal strips of the non-denaturing 
polyacrylamide gels was sufficiently pure to permit amino acid sequencing, in which case samples were applied directly onto the membranes for sequencing. When the fractions contained too many comigrating proteins they were re-run on an SDS-gel and subsequently transferred onto membranes by electro-blotting.

Several polyacrylamide gel systems $(9,11)$ and diverse membrane filters were tested to find the optimal condition for the preparation of proteins suitable for sequencing. Electrophoresis in the Tricine-SDS-gel system published by SCHÄGGER and JAGOW (14) and followed by electro-transfer onto PVDF-membrane (12) gave reproducibly high yields of protein suitable for sequencing.

The Tricine-SDS-gel had a high resolution for proteins with high molecular weights as well as for small peptides. Therefore it was equally suited for the analysis of the uncleaved aminotransferase and its cleavage products. A low concentration of polyacrylamide could be used for more effective transfer of the protein to the membranes and prevented disturbance and $\mathrm{NH}_{2}$-terminal blockage of the protein.

The peptides cleaved with cyanogen bromide were electro-blotted according to the same protocol as the complete proteins with the exception that the transfer buffer contained $20 \%$ methanol. In Figure 5 several cyanogen bromide fragments of the barley aminotransferase are detectable in the range between 17,000 and $2,000 \mathrm{Da}$. The $17 \mathrm{kDa}$ peptide was strongly stained by Coomassie Blue and recognized by the antibody against the barley aminotransferase. This peptide was transferred onto the PVDF-membrane and its $\mathrm{NH}_{2}$-terminal amino acid sequence determined.

\subsection{Partial amino acid sequence of the aminotransferase}

The $\mathrm{NH}_{2}$-terminal amino acid sequences of the complete aminotransferase of barley and Synechococcus and the $17 \mathrm{kDa}$ cyanogen bromide fragment of the barley protein are presented in Figure 6. The mature barley aminotransferase, which is derived after cleavage of a transit peptide, has at its $\mathrm{NH}_{2}$-terminal end the amino acid residue alanine. The cyanobacterial en-

\section{Western blot, anti - glutamate 1-semialdehyde aminotrans- ferase}

NONDENA-
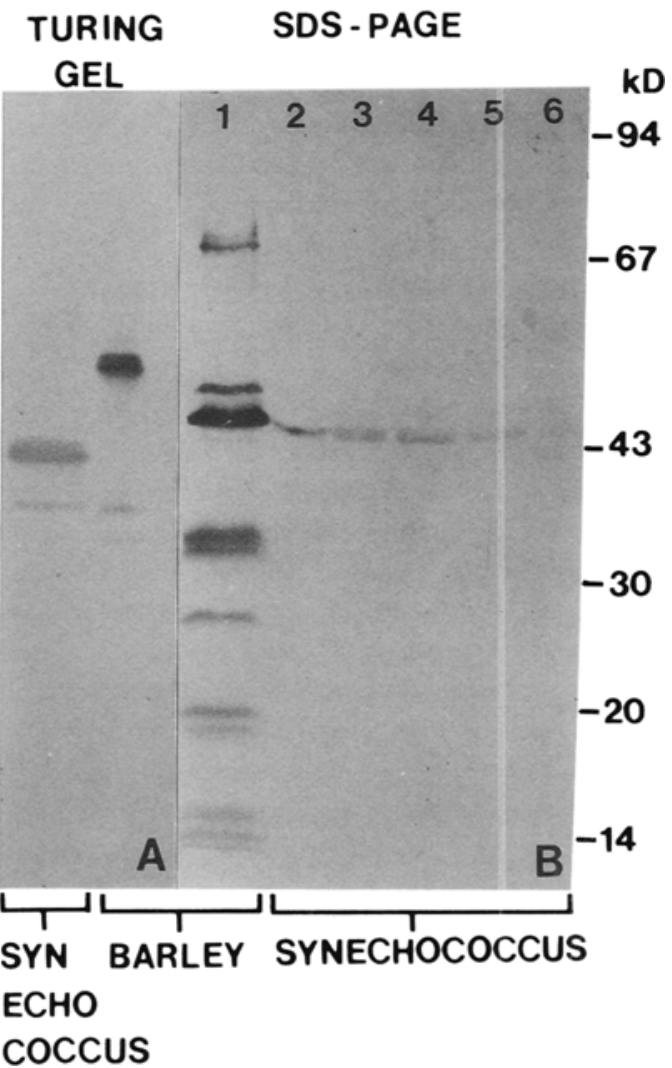

Figure 4. Proteins of the aminotransferase enriched fraction of barley and Synechococcus were subjected to Western blot analysis (alkaline phosphatase procedure, 2.6) with the antibody against the barley enzyme. A) shows immune-reacting protein of Synechococcus and barley separated in a non-denaturing gel. B) contains protein of barley (lane 1) and Synechococcus gel purified fractions (lane 2-6) obtained from $1 \mathrm{~mm}$ strips of the non-denaturing gels, applied to an SDS-gel and recognized by the antibody. In lane 4 the most active fraction of the Synechococcus preparation is positioned. The other lanes contain protein of the neighbouring fractions.

zyme begins with valine indicating the removal of the formyl-methionine from the nascent protein. 


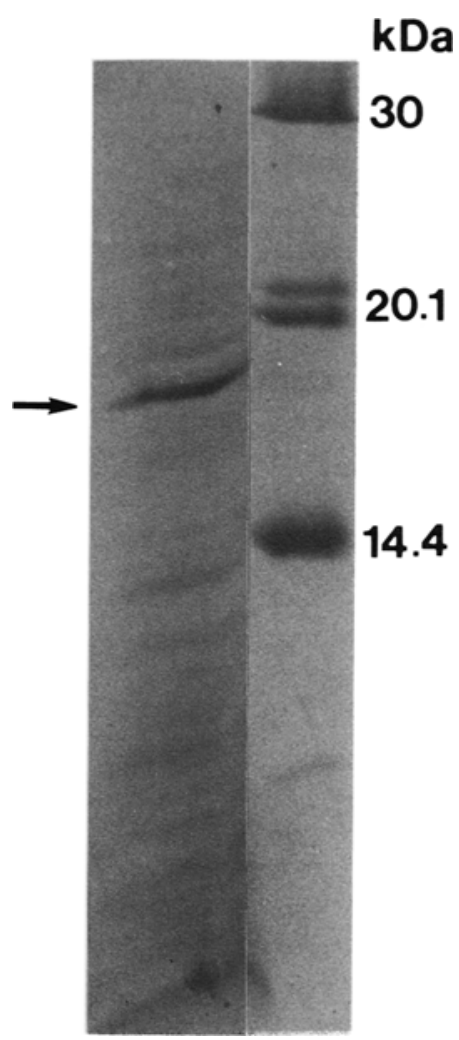

Figure 5. Separation of the cyanogen bromide cleaved peptides of the barley glutamate 1-semialdehyde aminotransferase by SDS-PAGE in a $16.5 \%$ gel. The peptides were stained with Coomassie Blue. The 17 $\mathrm{kDa}$ band used for amino acid sequencing is indicated by an arrow. Marker proteins were separated in the right lane.

The sequences of the $\mathrm{NH}_{2}$-terminal end of the proteins of barley and Synechococcus were aligned. Of the comparable 19 or 16 amino acid residues 11 are identical or conservative substi-

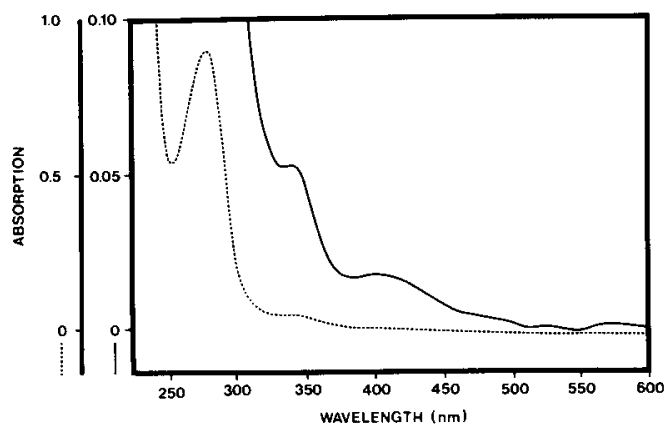

Figure 7. Absorption spectrum of the gel purified glutamate 1-semialdehyde aminotransferase from barley $(1 \mathrm{mg} / \mathrm{ml})$. Incubation of the enzyme with $25 \mathrm{~mm}$ levulinate at $28{ }^{\circ} \mathrm{C}$ for $30 \mathrm{~min}$ gave no change in the spectrum.

tutions. This indicates a significant homology in this domain between the cyanobacterial and plant glutamate 1-semialdehyde aminotransferase.

Comparison of the partial sequences of the glutamate 1-semialdehyde aminotransferase with sequences in the data bank did not reveal homology to other proteins.

The amino acid compositions of the two aminotransferases are given in Table I. From the number of methionines, nine cyanogen bromide cleavage fragments of the barley glutamate 1 -semialdehyde aminotransferase would be predicted.

\subsection{Absorption spectra of the purified barley glutamate 1-semialdehyde aminotransferase}

The absorption spectra of the purified glutamate 1-semialdehyde aminotransferase of bar-

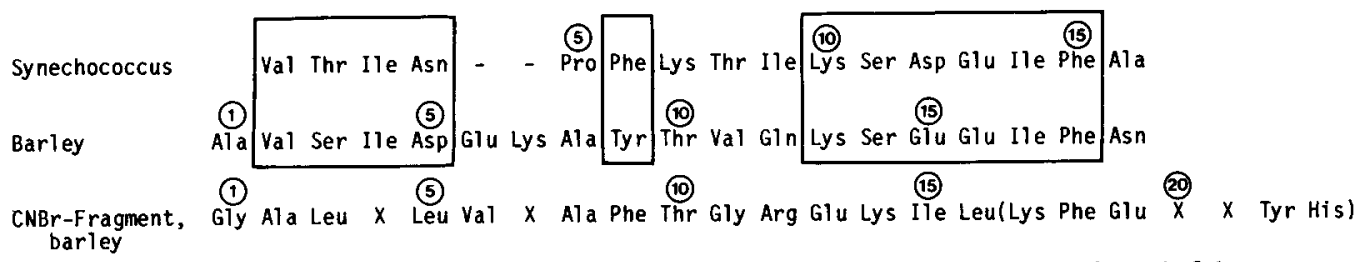

Figure 6. NH-terminal amino acid sequences of the Synechococcus and barley $46 \mathrm{kDa}$ protein and of the cyanogen bromide cleaved internal peptide obtained from the barley enzyme. The clearly homologous sequences are boxed. $\mathrm{X}$ indicates unidentified amino acid residues and - is introduced to obtain maximal homology. Sequence analyses were carried out twice or more. The sequence of amino acid residues in parantheses in the $\mathrm{CNBr}$ fragment was obtained in one analysis. 
Table I. Preliminary amino acid composition of the glutamate 1-semialdehyde aminotransferase of Synechococcus and barley. One sample of each was hydrolysed for $20 \mathrm{~h}$. Results are uncorrected.

\begin{tabular}{lcc}
\hline & $\begin{array}{c}\text { Glutamate l-semialdehyde aminotransferase } \\
\text { Barley }\end{array}$ & $\begin{array}{c}\text { Synechococcus } \\
\text { (mol/mol) }\end{array}$ \\
Asp & 34,2 & 28,6 \\
Thr & 25,4 & 23,9 \\
Ser & 20,2 & 19,2 \\
Glu & 47,4 & 47,5 \\
Pro & 26,0 & 24,0 \\
Gly & 24,1 & 53,0 \\
Ala & 53,7 & 51,2 \\
Cys & 4,0 & 4,6 \\
Val & 40,8 & 31,5 \\
Met & 8,0 & 11,3 \\
Ile & 21,6 & 21,7 \\
Leu & 42,5 & 39,4 \\
Tyr & 11,3 & 12,4 \\
Phe & 25,2 & 22,2 \\
His & 5,5 & 5,5 \\
Lys & 18,2 & 11,8 \\
Arg & 9,8 & 10,4 \\
\hline Total & 417,9 & 418,2 \\
\hline
\end{tabular}

ley is given in Figure 7. Incubation of the enzyme with $1 \mathrm{~mm}$ levulinate for $20 \mathrm{~min}$ at 28 ${ }^{\circ} \mathrm{C}$ - which serves as an amino group acceptor and is expected to convert the enzyme into the pyridoxal form (2) - did not change the spectrum. Thus no spectral evidence for the presence of pyridoxal phosphate in the barley aminotransferase could be obtained.

\subsection{Determination of the isoelectric point of the barley glutamate 1-semialdehyde aminotransferase}

The proteins precipitating between $30-70 \%$ ammonium sulphate were obtained from homogenized chloroplast supernatant. They were applied to two cycles of isoelectric focussing in order to determine the $\mathrm{pI}$ of the active glutamate 1 -semialdehyde aminotransferase. Twenty different fractions were obtained after the first separation and tested for aminotransferase activity. Glutamate 1-semialdehyde aminotrans- ferase was concentrated at $\mathrm{pH} 4.81+/-0.5$ (Fig. 8 ). Additionally, all fractions were assayed for aminolevulinate dehydratase and phorphobilinogen deaminase. PBG-deaminase co-migrated with the aminotransferase, while ALA-dehydratase was present at $\mathrm{pH} 5.61$.

After re-run of the aminotransferase containing fractions on the isoelectric focussing apparatus the aminotransferase activity was found at $\mathrm{pH} 5.10+/-0.1$. The $\mathrm{pI}$ of the PBG-deaminase was determined as $4.92+/-0.1$ in the $\mathrm{pH}$-gradient.

\section{DISCUSSION}

With two different separation techniques (non-denaturing PAGE and isoelectric focussing) it was possible to obtain glutamate 1 -semialdehyde aminotransferase. The enzyme lost its activity when the protein was analysed by SDS-PAGE.

Previous experiments to purify the glutamate 1-semialdehyde aminotransferase have been performed with Sephacryl S-300 filtration followed by chromotography on DEAE-Sephadex A 25, Sepharose 6B, Bio-gel A 0.5, Sephacryl S-200 and polyacrylamide disc gel electrophoresis $(3,5)$. During gel filtration the barley aminotransferase eluted in a molecular weight region of $80 \mathrm{kDa}(5)$.

One of the methods presented in this paper to purify the glutamate 1-semialdehyde aminotransferase efficiently utilizes the stroma protein fraction of barley which was passed through several affinity columns to remove contaminants before it is subjected to non-denaturing polyacrylamide gels. This procedure has the advantage that it also provides the other components of the $\delta$-aminolevulinate biosynthetic pathway, the tRNA ${ }^{\text {Glu }}$ ligase and the dehydrogenase, in the same experiment.

The isoelectric focussing procedure is simpler and can be performed directly with soluble proteins isolated from the greening leaves of barley. After two cycles of isoelectric focussing partially purified and enzymatically active aminotransferase can be obtained.

Purified barley glutamate 1-semialdehyde aminotransferase migrates as a single $46 \mathrm{kDa}$ polypeptide in SDS-PAGE. This finding together 


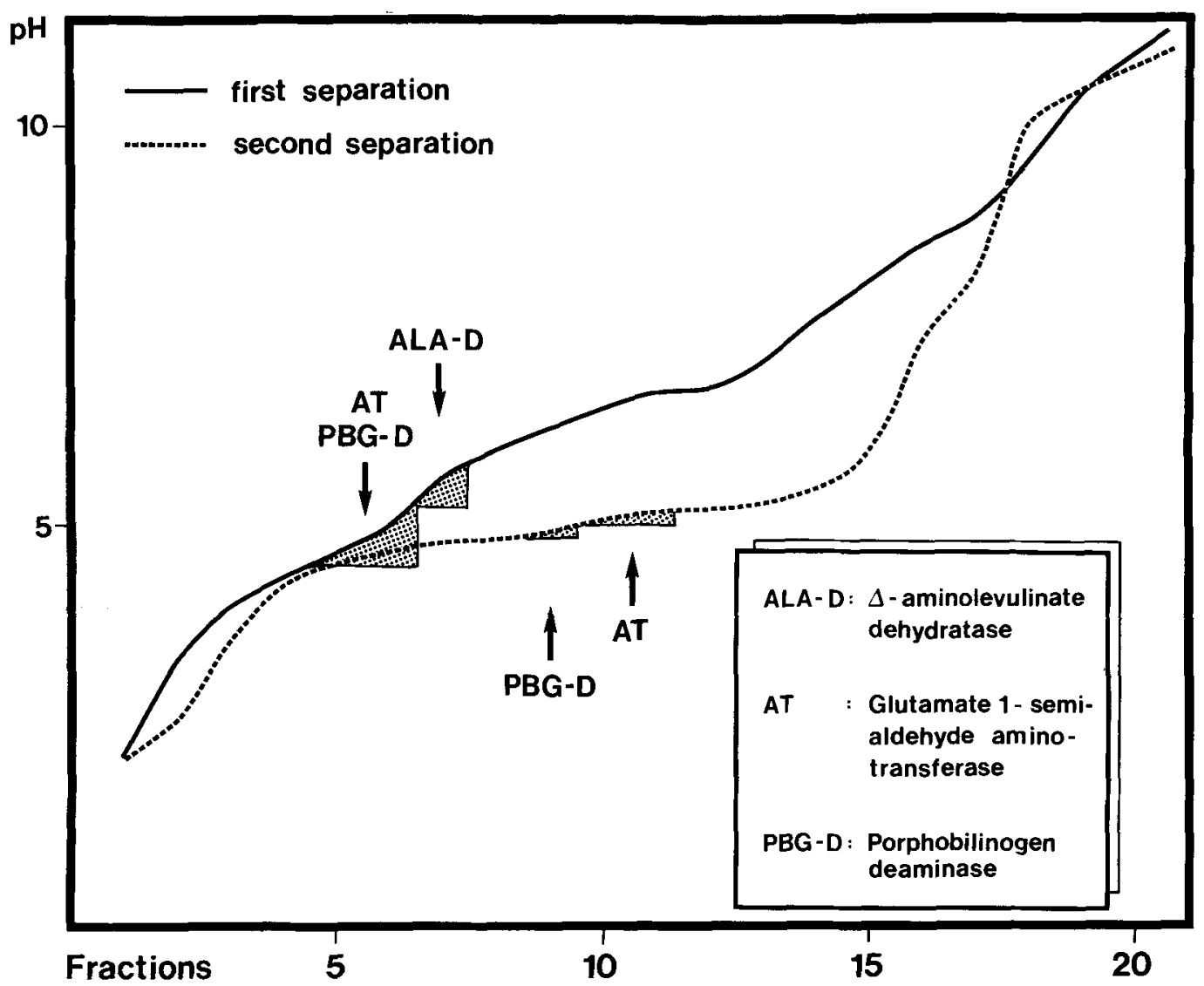

Figure 8. Preparative isoelectric focussing of barley protein precipitating between 30-70\% ammonium sulphate saturation. After the first separation the position of the aminotransferase (AT), PBG-deaminase (PBG-D) and ALA-dehydratase (ALA-D) in the $\mathrm{pH}$-gradient were determined by measuring their enzymatic activities. The two fractions containing AT and PBG-D were subjected a second time to isoelectric focussing. Both enzymes were detected again by enzymatic assays and their positions are shown in the pH-gradient marked with the dotted line.

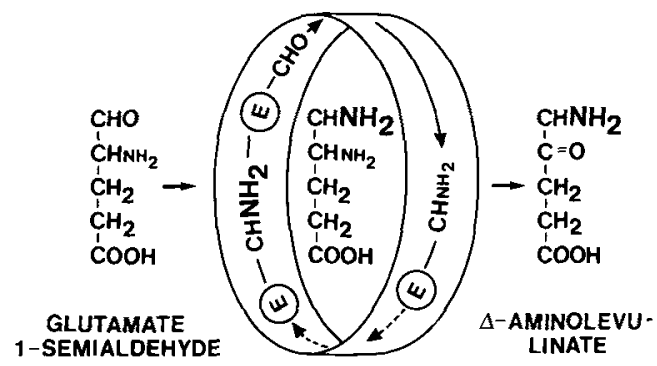

Figure 9. Catalytic mechanism proposed for the glutamate 1-semialdehyde aminotransferase. An amino group is donated to glutamate 1-semialdehyde to form 4,5-diaminovalerate and the aldehyde form of the enzyme. The intermediate transferred back the 4-amino group to the enzymes. This produces aminolevulinate and regenerates the enzyme. with its behaviour during gel filtration indicating a molecular weight of $80 \mathrm{kDa}(5)$ and a single $\mathrm{NH}_{2}$-terminal amino acid sequence indicates that the glutamate 1-semialdehyde aminotransferase consists of two identical subunits.

Synechococcal glutamate 1-semialdehyde aminotransferase eluted from the Sephacryl S300 column as a molecule with smaller mass as compared to the barley enzyme. After SDSPAGE, however, a single protein with an apparent molecular mass of $46 \mathrm{kDa}$ was found. Furthermore, the Synechococcal enzyme migrates faster in a non-denaturing gel than the barley enzyme. We deduce that the cyanobacterial enzyme consists of a single polypeptide with the same molecular weight as the barley subunit. 
The $46 \mathrm{kDa}$ proteins of barley and Synechococcus show more than $50 \%$ amino acid sequence homology at the $\mathrm{NH}_{2}$-terminus indicating significant similarity in the primary structure of the plant and cyanobacterial aminotransferase.

Many aminotransferases contain pyridoxal phosphate as a cofactor. Pyridoxal phosphate absorbs light at $390 \mathrm{~nm}$. If it is linked to proteins it shows a characteristic absorption maximum between 410 and $430 \mathrm{~nm}$ (10). No pyridoxal phosphate could be detected by absorption spectroscopy of the purified barley aminotransferase. Since the enzyme was active and required no added pyridoxal phosphate or pyridoxamine phosphate for activity it cannot be excluded that instead of pyridoxal phosphate another component serves as a cofactor in the barley enzyme.

In contrast to the barley enzyme the glutamate 1-semialdehyde aminotransferase of Synechococcus is significantly stimulated by the addition of pyridoxamine phosphate. In the enzyme assay with freshly isolated enzyme the addition of $300 \mu \mathrm{M}$ pyridoxamine phsophate increased the rate from $5.25 \mathrm{nmole}$ ALA mgprotein, $\min ^{-1}$ to 8.1 nmole ALA mg ${ }^{-1}$ protein, $\mathrm{min}^{-1}$. Addition of pyridoxal phosphate does not effect the enzyme activity (BULL et al., in preparation).

The mechanism of transamination proposed for the glutamate 1-semialdehyde aminotransferase (Fig. 9) is well supported by the results obtained with the purified cyanobacterial enzyme. The active form of the enzyme carries an amino group which is donated to the substrate. In Synechococcus it is provided by pyridoxamine phosphate while in barley possibly by another donor, e.g. a second molecule of glutamate 1 -semialdehyde (8). The resulting intermediate is 4,5-diaminovalerate. The enzyme then removes the amino group at position 4 of this intermediate and releases $\delta$-aminolevulinate.

The knowledge of the $\mathrm{NH}_{2}$-terminal and an internal amino acid sequence of the glutamate 1-semialdehyde aminotransferase provides the possibility to synthesize DNA primers encoding stretches of the sequence. With the aid of such oligonucleotides and the polymerase chain reaction we have cloned a DNA fragment of 460 nucleotides. This fragment served as probe for the identification of cDNA clones. Their se- quences will be presented in a forthcoming paper.

\section{ACKNOWLEDGEMENTS}

We thank Prof. D. v. WETtSTeIN for his support. We thank Nina Rasmussen, ANN-SoFI STEINHOLTZ and ANNE BLICHER for technical assistance. B.G. was supported by a postdoctoral fellowship of the Deutsche Forschungsgemeinschaft and of the European Molecular Biology Organization.

\section{REFERENCES}

1. HøNBERG, L.S.: Probing barley mutants with a monoclonal antibody to a polypeptide involved in photosynthetic oxygen evolution. Carisberg Res. Commun. 49, 703-719 (1984)

2. HoOber, J.K., A. KahN, D.E. ASH, S.P. GoUGH \& C.G. Kannangara: Biosynthesis of $\delta$ aminolevulinate in greening barley leaves. IX. Structure of the substrate, mode of gabaculine inhibition, and the catalytic mechanism of glutamate 1-semialdehyde aminotransferase. Carlsberg Res. Commun. 53, 11-25 (1988)

3. Kannangara, C.G. \& A. Schouboe: Biosynthesis of $\delta$-aminolevulinate in greening barley leaves. VII. Glutamate 1-semialdehyde accumulation in gabaculine treated leaves. Carlsberg Res. Commun. 50, 179-191 (1985)

4. Kannangara, C.G., S.P. Gough, P. Bruyant, J.K. HoOber, A. KaHN \& D.v. WeTtSTEIN: tRNA glu as a factor in $\delta$-aminolevulinate biosynthesis: steps that regulate chlorophyll synthesis. TIBS 13, 139143 (1988)

5. KanNangara, C.G., S.P. Gough \& C. GiRnth: $\delta$ aminolevulinate synthesis in greening barley. 2 . Purification of Enzymes. In: 5th Int. Congr. Photosynthesis V. Chloroplast development. G. Akoyunoglou ed., Balaban International Science Services, Philadelphia, pp. 117-127 (1981)

6. Kannangara, C.G., S.P. Gough, R.P. Oliver \& S.K. RASMUSSEN: Biosynthesis of $\delta$-aminolevulinate in greening barley leaves. VI. Activation of glutamate by ligation to RNA. Carlsberg Res. Commun. 49, 417-437 (1984)

7. KYHSE-ANDERSEN, J.: Electroblotting of multiple gels: a simple apparatus without buffer tank for rapid transfer of proteins from polyacrylamide to nitrocellulose. J. Biochem. Biophys. Meth. 10, 203-209 (1984)

8. MAU, Y.-H. \& W.-Y. WANG: Biosynthesis of $\delta-$ aminolevulinic acid in Chlamydomonas reinhardtii. Plant Physiol. 86, 793-797 (1988) 
9. Moos, M. JR., N.Y. NGUYEN \& T..Y. LIU: Reproducible high yield sequencing of proteins electrophoretically separated and transferred to an inert support. J. Biol. Chem. 263, 6005-6008 (1988)

10. MoRino, Y. \& F. Nagashima: Pyridoxal phosphate-binding site in enzymes; reduction and comparison of sequences. In: Methods in Enzymology, Vol. 106, Colowick, S.P. \& N.O. Kaplan (ed.), Academic Press, Inc., pp. 116-137 (1984)

11. NEVILLE, D.M.: Molecular weight determination of protein-dodecyl-sulphate complexes by gel electrophoresis in a discontinuous buffer system. J. Biol. Chem. 246, 6328-6334 (1971)

12. Ploug, M., A.L. Jensen \& V. Barkholt: Determination of amino acid composition and $\mathrm{NH}_{2}$-terminal end of peptides electroblotted onto PVDF- membrane from Tricine-SDS-Gels. Application to peptide mapping of human complement components. Anal. Biochem. in press (1989)

13. Rippka, R., J. Dernelles, J.B. Waterbury, M. HERDMAN \& R.Y. STANIER: Generic assignments, strain history and properties of pure cultures of cyanobacteria. J. Gen. Microb. 111, 1-61 (1979)

14. SCHÄGGER, H. \& G.V. JAGOW: Tricine-sodium dodecyl sulfate-polyacrylamide gel electrophoresis for the separation of proteins in the range from 1 to $100 \mathrm{kDa}$. Anal. Biochem. 166, 368-379 (1987)

15. WANG, W.Y., S.P. GougH \& C.G. KanNangaRa: Biosynthesis of $\delta$-aminolevulinate in greening barley leaves. IV. Isolation of three soluble enzymes required for the conversion of glutamate to $\delta$ aminolevulinate. Carlsberg Res. Commun. 46, 243-257 (1981)

Accepted by H. KLENOW 